\title{
El vuelo del Angelus Novus por los campos de refugiados de Tinduf. Cavilaciones benjaminianas ${ }^{1}$
}

\author{
Angelus Novus Flying over the Tinduf \\ Refugee Camps. Benjaminian Musings
}

\author{
Silvana Rabinovich \\ Universidad Nacional Autónoma de México \\ Instituto de Investigaciones Filológicas \\ silvanarabk@gmail.com \\ orcid.org/oooo-0oo2-9648-4155
}

Resumen: Walter Benjamin comparaba a las citas con "salteadores" en medio del camino de lectura. En el presente artículo, un tiempo de interrupción que acostumbra a sacar de contexto palabras lejanas marcará el ritmo de la escritura, rememorando una experiencia de hospitalidad entre los nómadas. Así, en un ejercicio de memoria crítica cuya figura emblemática es el ángel de la historia benjaminiano, evocaremos algunas visitas a los campos de refugiados del Sáhara Occidental. Entre figuras derridianas de hos(ti)pitalidad, autores de latitudes lejanas, como el poeta palestino Mahmud Darwish, el escritor argentino Juan José Saer o el naturalista francés Théodore Monod, entre otros, se darán cita en las páginas que siguen intentando explicar el imposible vuelo del Angelus Novus.

Palabras clave: Sáhara Occidental, campos de refugiados, nómadas, hospitalidad, Angelus Novus

Abstract: Walter Benjamin used to compare quotes with "waylayers" in the path of reading. In the present article, putting distant words out of context will set a constantly interrupted rhythm of writing, emulating the experience of hospitality among nomads. Thus, in an exercise of critical memory whose emblematic figure is the Benjaminian Angel of History, we will evoke visits to the refugee camps in Western Sahara. Among Derridian figures of hos(ti)pitality, authors from distant places, such as the Palestinian poet Mahmud Darwish, the Argentinian writer Juan

1 Esta investigación fue realizada gracias al apoyo del Proyecto PAPITT IN 401119 "Heteronomías de la justicia: territorialidades nómadas". 
José Saer, or the French naturalist Théodore Monod, among others, will be gathered in quotes in these pages that will keep on trying to explain the impossible flight of Angelus Novus.

Keywords: Western Sahara, refugee camps, nomads, hospitality, Angelus Novus

Recibido: $\quad 30$ de agosto de 2019

Aceptado: $\quad 23$ de noviembre de 2019

\section{Aterrizaje}

Tinduf es una base aérea militar ubicada en el extremo occidental de Argelia. Allá llegan y despegan también aviones civiles. Un número considerable de los pasajeros de la línea aérea comercial que arriba a ese lugar tiene por destino los campos de refugiados del Sáhara Occidental, a los cuales se accede por tierra y con escolta saharaui. Se trata de un territorio cedido por el gobierno argelino a la República Árabe Saharaui Democrática (RASD), que tiene la particularidad de ser, desde su proclamación en 1976, una república en el exilio. En lo que sigue, proponemos una revisita a los campos de refugiados por el bies de ciertas paradojas que entrañan una añeja injusticia.

\section{Trabalenguas colonial: Con una excolonia recolonizadora... Colón "descolonializó"}

No prometeros algo, sino comprometerme con la historia. Nuestro partido estará con vosotros hasta la victoria final.

Felipe González al pueblo saharaui, 14/11/1976

Te olvidaste de la Historia, alguien que no perdona. Recuerda lo que ha pasado, aunque ya no haya remedio. ¡Felipe, escúchame lo que te canto y te digo! Te creímos de verdad y fallaste al completo. Mira, que la espina se oculta entre pétalos de rosa ¡Oh Felipe, Felipe! Y su veneno es mortal.

Mariem Hassan, 2 "La espina”

2 Respuesta de Mariem Hassan, en forma de cantata popular, al discurso que Felipe González pronunció el 14-11-1976 en los campamentos de refugiados saharauis de 
Territorio fallidamente descolonizado por España en 1975, el Sáhara Occidental (aún hoy considerado desde el punto de vista jurídico bajo administración española) está ocupado por el reino de Marruecos. La ocupación se dio a partir de un llamado que hizo ese mismo año el rey Hassan II a la población civil marroquí, para emprender la "marcha verde" a fin de colonizar los territorios del pueblo beduino hispanoparlante (Barona y Arenas 2016: 59). Acudieron a este llamado unos 350 ooo marroquíes, que cruzaron la frontera hacia el sur (Beristáin et al. 2015: 12). Tierra rica en fosfatos, petróleo, gas, célebre por la codiciada pesca en sus costas, así como por las napas de agua dulce (donde los verdaderos zahoríes son camélidos), el Sáhara Occidental fue entregado por España a Marruecos y Mauritania (Martínez 1991). Esto ocurrió el 14 de noviembre de 1975, en Madrid, en un acuerdo tripartito secreto que traicionaba la promesa previa hecha a los representantes legítimos del pueblo saharaui, excluidos de dicho pacto: el Frente Polisario. 3 Las vanas promesas de Felipe González, así como el reclamo en la voz rebelde de la cantante Mariem Hassan (ambos citados en el epígrafe), aluden a una responsabilidad que el político español ignoró cuando asumió el poder.

Ese año, hombres y mujeres combatientes salieron de su territorio con una considerable población de todas las edades que fue bombardeada por la fuerza aérea marroquí con napalm y fósforo blanco mientras buscaban refugio por el desierto (Beristáin et al. 2015: 17 y ss.). El 27 de febrero de 1976, en Bir Lehlu, se proclamó la independencia de la RASD. 4 La otra parte de la población permanece desde entonces bajo un régimen de ocupación que viola los derechos de los pobladores originarios con notoria crueldad (Beristáin y González 2012). La máquina de guerra beduina (Deleuze y Guattari 2015: 359 y ss.), conocedora del territorio como solo los nómadas pueden hacerlo, desgastaba al ejército de la excolonia francesa ocupante, que en 1991 pidió una tregua para dar paso a un referéndum de autodeterminación, que el Frente Polisario aceptó, deponiendo las armas.

Tinduf. Letra en Schubert-Wurr y Domínguez (2017: 163). Música en: <https://www. youtube.com/watch? $\mathrm{v}=\mathrm{c} 9 \mathrm{WnazvAl} 2 \mathrm{I}>$, consultado por última vez el 22 de noviembre de 2019.

3 Para su descolonización, la Yema'a, consejo de ancianos que representaron al pueblo saharaui ante la colonia española, cedió su representación al Frente Polisario (Frente de Liberación de Saguia al Hamra hasta Río de Oro). Cf. Carolina Jiménez Sánchez, 2014.

4 República Árabe Saharaui Democrática. 


\section{Un armisticio... ¿para proteger las minas antipersonas?}

En el centro clandestino de Kalaat M'gouna, donde todo estaba prohibido, se hizo el único referéndum de autodeterminación realizado hasta ahora. No necesitaron resoluciones de Naciones Unidas, siempre incumplidas. Solo la voluntad. La expresión de una libertad que aún hoy en día espera, empuja y defiende la vida.

Beristáin, "Memorias nómadas"

Hoy, el pueblo saharaui está dividido por un muro hecho de piedras, arena, alambres de púas, trincheras y radares cuya longitud es de $2720 \mathrm{~km}$, construido por Marruecos en seis etapas, entre 1980 y 1987. De apenas dos metros de altura y compuesto de elementos poco sofisticados, este muro impide el retorno de los exiliados, por estar completamente "sembrado" con entre siete y diez millones de minas antipersonas y anticarros (Braica 2006: 3). La población saharaui, según el comandante Habuha Braica, es "el grupo humano amenazado por más minas por persona del mundo” (2006: 3). También los animales no humanos lo están, y eso es un dato fundamental para la vida de una población de raigambre nómada.

Los exiliados, acogidos por Argelia por razones administrativas de la ONU, se establecieron en cinco campamentos de refugiados o wilayas que llevan los nombres de sus lugares añorados: Samara, El Ayún, Dajla, Ausserd y Bojador. Depuestas las armas, la Minurso (Misión de Naciones Unidas para el Referéndum del Sáhara Occidental) se comprometió a propiciar la votación para la autodeterminación del pueblo saharaui. En dicho referéndum, los árabes hispanófonos de lengua materna hasanía, deberían decidir si volverse una región autónoma de Marruecos (país francófono, de lengua dariya) o una república completamente independiente. Desde 1991 la política marroquí (que se beneficia de la explotación de fosfato, petróleo, gas y pesca saharauis por parte de compañías multinacionales) vicia el mecanismo de referéndum prolongando el exilio de la mitad de la nación saharaui y sometiendo a la otra mitad, que está bajo su ocupación, a constantes vejaciones a los derechos humanos. 5 Llama la atención que la ONU no insista en la urgencia humani-

5 El caso emblemático de la luchadora por los derechos humanos Aminetu Haidar estuvo en las noticias en 2010 por una huelga de hambre de 32 días (y por eso se la 
taria de desminar el vasto territorio lindante con el muro. Por el contrario, sorpresivamente, a finales de 2018 las dos ONG encargadas de dicha tarea rescindieron unilateralmente y sin explicaciones contratos que debían durar dos años más, quedando únicamente bajo proceso de desminado el paso reservado a la Minurso. ${ }^{6}$ Da la impresión de que la Minurso custodia las minas de Marruecos en lugar de buscar por todos los medios la realización efectiva del referéndum que explica su presencia en el lugar.

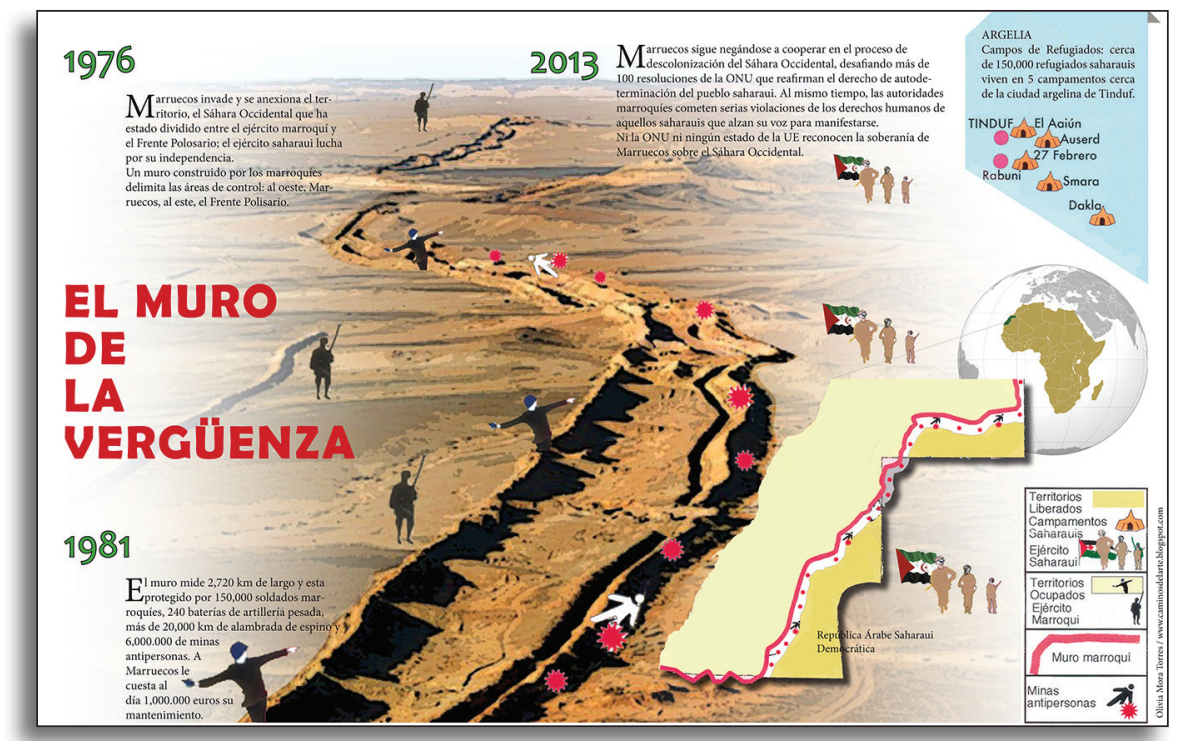

Infografía con imagen del muro, realizada por Olivia Mora para la embajada de la RASD en México (2013).

conoce como la Gandhi africana). El motivo de dicha huelga fue que las autoridades de Marruecos le negaron la entrada a su tierra, pues había escrito en su formulario de entrada al aeropuerto de El Ayún "nacionalidad saharaui" en lugar de "marroquí" (Moya 2010).

6 En una entrevista que tuvo lugar el 10 de marzo de 2018, Malainin Mohamed Brahim, director de SMAco (Saharawi Mine Action Coordination Office), informó a los miembros del mencionado proyecto PAPIIT que el NPA (Norwegian People's Aid) había interrumpido abruptamente sus actividades, dejando minas descubiertas sin desactivar, e impidiendo a los saharauis usar el equipo que, según dijeron, sería enviado a Angola. Asimismo, nos confirmó que la única compañía que continuaba la tarea de desminado sería DML (Dynasafe Minetech Limited), cuyos equipos son directamente financiados por la Minurso y sirven estrictamente a sus necesidades. Esto es sumamente peligroso: las dunas se mueven con el viento cubriendo lo descubierto y descubriendo otras minas activas. Dejar minas descubiertas sin desactivar es un acto criminal. 


\section{Desobediencia debida}

[...] parecía imposible, pero lo hicimos.

Beristáin, "Memorias nómadas"

Además de la ayuda proveniente de instituciones internacionales, llama la atención el compromiso inquebrantable de numerosas organizaciones de la sociedad española que asumen la responsabilidad ignorada por los distintos gobiernos españoles centrales por más de 43 años. Programas como "vacaciones en paz" estrechan lazos entre familias y permiten a los niños saharauis salir del durísimo verano de la Hamada argelina hacia España: familias de acogida que se adoptan mutuamente en actos sostenidos de hospitalidad genuina, universidades españolas que dedican programas y sostienen convenios con la red educativa saharaui en todos sus niveles, y apoyan en tareas de defensa de los derechos humanos en los territorios ocupados y asesoran a los familiares de presos y desaparecidos. Incluso en niveles medios de gobierno, las comunidades de España se hacen responsables a través de diversos programas. Por otra parte, médicos sin fronteras, artistas, ingenieros sin fronteras, maestros y médicos cubanos -y de otras nacionalidades- expresan efectivamente su solidaridad incondicional con el pueblo saharaui que resiste sin violencia a la injusticia. Cabe destacar que Cuba ha desempeñado ininterrumpidamente, aun en su "periodo especial", un papel clave en la educación de los niños y jóvenes saharauis, acogiéndolos en diversas escuelas hasta completar estudios de nivel universitario. Además, otros países de nuestro continente, como Venezuela, también se solidarizan con la educación en los campamentos.7

El tránsito de activistas, políticos y personas solidarias del mundo que, por décadas y sin pausa, visitan los campamentos de refugiados, propició que, en los últimos años, la población de Tinduf haya crecido debido al desarrollo comercial. Este dato suscita preguntas: ¿puede extenderse por décadas el estatuto de "refugiado"? ¿Qué es lo que crece con el "crecimiento económico" en el desierto?

7 Sorprende al visitante latinoamericano ver en un paisaje sahariano la imagen de Simón Bolívar con su nombre escrito en letras árabes, al frente de una escuela, fundada en 2011 por el gobierno de Venezuela. 


\section{Normalización de lo anómalo}

[...] nadie quiere saber que la historia contemporánea ha creado una nueva clase de seres humanos: la clase de los que son confinados en campos de concentración por sus enemigos y en campos de internamiento por sus amigos. Arendt, "Nosotros, los refugiados"

Aunque, por definición, el estatuto de refugiado es temporal —efímero- el pueblo saharaui ha visto nacer en esos campos a dos generaciones. Acorralado 43 años en los campamentos de ACNUR, ubicados en la hamada argelina. Paradójicamente, siendo la parte más inhóspita del desierto - su nombre designa la nada-, la hamada asila a un pueblo beduino que hace de la hospitalidad su forma de resistencia. En efecto, durante este mal llamado "alto al fuego" con el reino de Marruecos, que mantiene a la otra mitad del pueblo bajo una ocupación criminal (Beristáin y González 2012, Beristáin y Etxeberria 2013), ${ }^{8}$ los saharauis politizan hoy esta tradición ancestral para dar a conocer su causa. De "este lado" de un muro infame, desde un exilio prolongado por los organismos internacionales, 9 la RASD ve a la Minurso postergar desde 1991 su referéndum de autodeterminación (promesa por la cual el Frente Polisario depuso las armas). ${ }^{10}$

"Sedentariza y controlarás": con el pretexto de la ayuda internacional (cuya importancia aquí no se cuestiona), los nómadas son sedentarizados y obligados así a permanecer en una dependencia que los sitúa en las antípodas de su tradición trashumante, caracterizada por ser radicalmente insumisa (Ibn Jal-

8 El video de Democracy Now, Four days in occupied Western Sahara presenta una investigación nutrida y valiente por parte de Amy Goodman y su equipo, publicado en agosto de 2018, en <https://www.youtube.com/watch?v=smg97ib_yfM>, consultado por última vez el 22 de noviembre de 2019.

9 <https://peacekeeping.un.org/es/mission/minurso>, consultado por última vez el 22 de noviembre de 2019.

10 Aprobada por unanimidad el 29 de abril de1991, la resolución 690: “[...] 2. Expresa su apoyo total a los esfuerzos del Secretario General en relación con la organización y supervisión por las Naciones Unidas, en cooperación con la Organización de la Unidad Africana, de un referéndum de libre determinación del pueblo del Sáhara Occidental, de conformidad con los objetivos mencionados en el informe del Secretario General. [...] 4. Decide establecer bajo su autoridad una Misión de las Naciones Unidas para el Referéndum del Sáhara Occidental [...]” en <https://undocs.org/es/S/ RES/690> (1991), consultado por última vez el 22 de noviembre de 2019. 
dún 2008: 212 y ss.). En los campamentos de refugiados de Tinduf, en medio del estancamiento forzado del brío nómada, anida la obstinada esperanza de la liberación. Me referiré a continuación a este lado del muro minado, el que impide el retorno de los exiliados. ${ }^{11}$

\title{
Hos(ti)pitalidad: una república en el exilio
}

\author{
Oh, [hay] bastante esperanza, infinita esperanza, solo que \\ no para nosotros.
}

Kafka en Benjamin

De "este" lado, ${ }^{12}$ el de los campos de refugiados, el Frente Polisario conduce la mencionada república en el exilio: la RASD, que ha sido reconocida por decenas de Estados entre los cuales, desde 1979, se cuenta a México. ${ }^{13}$ Se trata de una organización que lleva adelante una red de educación, salud, administración de la ayuda internacional, representación política, sobre todo con miras al reconocimiento del derecho del pueblo saharaui a su autodeterminación tanto en el nivel de política oficial con los Estados, como de su base social (el cultivo de la relación entre los pueblos, promoviendo las visitas de

11 No podría hablar del otro lado porque no lo he visitado (hay trabas para entrar a quien estuvo en los campamentos de Argelia). Sin embargo, tanto por el valiosísimo trabajo que realizó, mientras le fue permitido entrar en los territorios ocupados, el psicólogo Carlos M. Beristáin y su equipo, o por la información que llega desde allí por las redes sociales, como los jóvenes comunicadores de Nushatta, se puede apreciar el grado de violencia que padecen los saharauis bajo la ocupación marroquí, en <https:// noteolvidesdelsaharaoccidental.org/nushatta-foundation-clouds-of-tension-risein-western-sahara>, consultado por última vez el 22 de noviembre de 2019. Por otro lado, en los campamentos de refugiados entrevistamos varias veces a miembros de Afapredesa (Asociación de Familiares de Presos y Desaparecidos del Sáhara Occidental). Datos importantes se muestran en el video de Democracy Now mencionado antes (nota 9).

12 Expreso así el deíctico porque considero que los mexicanos nos encontramos "del mismo lado" de otro muro, es decir, de los impedidos de pasarlo (o, parafraseando la canción popular, de aquellos por encima de quienes pasó el muro). Los Tigres del Norte "Somos más americanos": "yo no crucé la frontera, la frontera me cruzó”, en <https://www.youtube.com/watch?v=LN3obcuoebo >, consultado por última vez el 22 de noviembre de 2019 .

13 El 8 de septiembre de 1979 México reconoció oficialmente a la RASD (lo anunció el entonces secretario de Relaciones Exteriores, Jorge Castañeda, y desde ese año se establecieron las relaciones diplomáticas entre ambos países). 
invitados, organizaciones y delegaciones a los campamentos). Así, la hospitalidad - tradicional - se actualiza como forma de resistencia. De las tensiones etimológicas propias de la "hospitalidad" que nos han sido reveladas por Benveniste (1966: 87 y ss.), en cuyo seno conviven hospes y hostis, Derrida (2000) acuñó el neologismo hostipitalidad (para distinguir la "hospitalidad de invitación" de la "hospitalidad de visitación"). Me interesaría señalar aquí cómo este entrecruzamiento de hospitalidad y hostilidad se manifiesta en la experiencia de los refugiados saharauis. Se trata de la visitación (o asedio) del "progreso" (que se resume en la acumulación de las mercancías) en su afán por tomar como rehén a la máquina de guerra nómada (Deleuze y Guattari 2015: 384 y ss.) que habita la memoria transgeneracional.

\section{(F)utilidad del asistencialismo}

Un viejo camión de la llanura alcanza, por las vicisitudes de su propia evolución, ese estatuto envidiable de objeto único que es la finalidad del arte, y las cimas de lo sublime no están lejos cuando, después de una larga carrera terrestre, naufraga, inmovilizado y recubierto de herrumbre, como Job del polvo rojizo que arrojaba por encima de su cabeza, en algún patio trasero recubierto de hierba salvaje, ya despojado del atributo esterilizante de la utilidad.

Saer, "El río sin orillas"

El malestar de 43 años de refugiados tiene algunos visos intergeneracionales dolorosos. La generación del exilio guarda dignidad mientras padece todo tipo de dolencias: llagas de una memoria atroz provocada por los estragos de las minas, los bombardeos con napalm y fósforo blanco. ${ }^{14}$

14 Esta memoria brutal se actualizó en octubre de 2010, durante un mes, en los territorios ocupados. La primavera árabe inició en Gdeim Izik el 10 de octubre de 2010, a escasos kilómetros de la capital El Ayún, en el "campamento de la dignidad” y terminó el 8 de noviembre de 2010 con extrema violencia desplegada por las fuerzas marroquíes, presos políticos, tortura, muertes... Documental Gdeim Izik. El campamento de la resistencia saharaui (dir. Lluís María Güell 2011), en <https://www.youtube.com/ 
La generación que le sigue, cuando no logra agenciarse ${ }^{15}$ del "progreso" (como lo hacen quienes animan la escuela de cine, ${ }^{16}$ por ejemplo, o las Bibliotecas Bubisher, ${ }^{17}$ entre tantas iniciativas geniales), queda aplastada por un amasijo hecho de lo más opresor de la tradición con la artillería pesada de un consumismo que muestra de manera obscena su futilidad. Así, la ayuda alimentaria llega con las enfermedades que la tecnología adjunta en la ayuda médica buscará sanar. ${ }^{18}$ (El "indio" del poema lo dice cabalmente: “[...] y estaríamos aquí/ construyendo aún más si no fuera por los fusiles de Inglaterra y el vino francés y la influenza" [Darwish 2017: 22]).

Así, la ayuda humanitaria, aun cuando está guiada por las mejores intenciones, muestra el límite del altruismo (cuyo horizonte es la justicia para el otro, porque no logra intuir la justicia del otro...). ${ }^{19}$ Los claroscuros de la vida en los campamentos siguen el pulso de transformaciones problemáticas (Langa 2016: 93 y ss.). Siguiendo la figura del Angelus novus benjaminiano: el torbellino de la acumulación se enreda en las alas de la tradición nómada,

watch?v=KT48osFZsbY>, consultado por última vez el 22 de noviembre de 2019. Para una versión novelada y crítica de esta historia, Mejía 2018.

15 Tomamos el término agenciamiento siguiendo la definición de Deleuze y Guattari: "todo conjunto de singularidades y de rasgos extraídos del flujo - seleccionados, organizados, estratificados-a fin de converger (consistencia) artificialmente y naturalmente: un agenciamiento, en este sentido, es una verdadera invención. Los agenciamientos pueden agruparse en conjuntos muy amplios que constituyen 'culturas'..." (2015: 408).

16 Escuela de Formación Audiovisual del Sáhara Occidental "Abidin Kaid Saleh", que se encuentra en el campamento de Bojador, en la cual se forman jóvenes saharauis que consideran al cine como una posibilidad de resistencia, para dar a conocer la situación de su pueblo en ambos lados del muro, en <http://www.escueladecinedelsa hara.org/>, consultado por última vez el 22 de noviembre de 2019.

17 Proyecto de bibliotecas y bibliobuses en los cinco campamentos de refugiados. Allí los niños saharauis pasan las tardes después de la escuela ocupados en actividades que alientan la lectura de manera creativa y lúdica, en <http://www.bubisher.org/>, consultado por última vez el 22 de noviembre de 2019.

18 La situación de salud en los campos de refugiados es crítica. Se relaciona con las preocupantes condiciones sanitarias. No pudiendo autoabastecerse, dependen de una ayuda alimentaria que trajo consigo - además de la sedentarización para poder ser suministrada - productos industrializados que provocan enfermedades imposibles de curar por la medicina tradicional. Muchos jóvenes saharauis salen a estudiar medicina en países solidarios (Cuba es el principal) y, si bien es una gran ayuda, acaba con la confianza en la tradición de curación. La salud mental es un capítulo aparte. Los traumas por la violencia padecida, así como la vida suspendida por un referéndum postergado por más de cuatro décadas, presentan un panorama desolado.

19 Para más detalles de esta diferencia, consultar a Rabinovich 2018. 
que insta a los hijos de las nubes (aulad almezna) a despojarse de todo bien superfluo. En nuestros tiempos industrializados dicha costumbre termina en regadíos de basura y suciedad (esto se explica porque tradicionalmente solo se desechaban residuos orgánicos...).

Queda al descubierto la (f)utilidad en la cual se funda la economía del "progreso". Aquí la "F", que en las tablas de verdad de la lógica designa lo falso, se antepone a la "utilidad" — meta de nuestra economía — para revelar su inherente insubstancialidad... Algo que Juan J. Saer calificó como los "acontecimientos descabellados" amasados por el "reino de la cantidad" (1991: 13).

La (f)utilidad económica marca un choque de temporalidades: la inmediatez impaciente de la proliferación de productos obsolescentes por el capitalismo industrial irrumpe en la suspensión de una espera que sabe a olvido internacional. La temporalidad suspendida en la espera se esfuerza por subsistir en la eternidad del desierto a través del ejercicio de paciencia heredado en el ritual del té, emblema de la hospitalidad. En esta tradición, los nómadas resisten hospitalariamente a la hostilidad del "progreso" que llega para sedentarizarlos.

\section{Contra el tedio de la miseria: ¿la acedía de la opulencia?}

Es [...] la perfección insensata de la civilización europea, en la que ya no se sabe dónde termina el confort y dónde empieza la pesadilla, lo que me parece más cercano a la demencia.

Saer, "El río sin orillas"

Mi tercera visita a los campamentos saharauis tuvo como objetivo participar activamente en la red de enseñanza en los niveles universitario y preuniversitario: la Universidad de Tifariti es uno de los esfuerzos por la difusión de la realidad saharaui en aras del reconocimiento internacional y por el intercambio de saberes. La mencionada escuela preuniversitaria Simón Bolívar (que cuenta con una mayoría de maestros cubanos) forma jóvenes de entre 13 y 17 años, en español y en árabe, quienes desarrollan un pensamiento crítico y político sorprendentes. ${ }^{20}$ Como siempre, la temporalidad beduina es reacia

20 Aunque, por obvias razones, es frecuente la politización de los niños refugiados. 
a las agendas y obliga a que todo programa se adapte a las posibilidades (que dependen tanto del siroco como de la factibilidad de reparación de viejos vehículos). Así, aquello que suele denominarse con la imposible expresión "tiempos muertos" revela el tedio de la miseria (cuya contraparte es la acedía de la opulencia, producto de nuestra cultura del ocio). ${ }^{21} \mathrm{Si}$ el tiempo se dilata en la hamada en una espera de la liberación que cada día parece alejarse más; se tensa en el ritmo estresante de nuestras megalópolis, que busca saciar su gula en el consumo. El tiempo del desierto se acopla a la espacialidad de un suelo que se mueve (podríamos decir que las dunas, al compás del viento, se vuelven suelo trashumante) marcando el camino en clave de los pozos de agua. El tiempo de la urbe está signado por la velocidad paralizante de las pantallas; aquellos pozos de agua - señales en el camino para saciar la sed y continuar con vida - se transforman aquí en pesadas construcciones de centros comerciales que alimentan nuestro insaciable apetito de acumulación.

Los campamentos se encuentran en la bisagra entre estos dos mundos tan distintos. Allí el brío rebelde de los nómadas, destacado por Ibn Jaldún (2008: 212 y ss.), no siempre logra apearse de las hordas del "progreso" que lo asedian de manera obscena: la fiebre del consumismo pretende maniatar a los beduinos para obligarlos a beber de sus cloacas. Tristemente, a veces la impotencia y el enojo de esta generación nacida en el exilio se impacienta con los niños. La hospitalidad con el futuro se vuelve inimaginable, la insubordinación nómada, sedentarizada a fuerzas, a veces se deja vencer por la hostilidad. (El tedio de la miseria no se puede tapar con el hastío esterilizante de la opulencia...)

\section{Florecer en el desierto}

Aquí no crecen árboles ni plantas, pero florecen personas. Dr. Castro

Sin embargo... la máquina de guerra no cesa de gestarse en todos lados. Esta es definida (Deleuze y Guattari 2015: 362) desde su "pura forma de exterioridad" respecto del aparato de Estado, al cual —según los filósofos— se suele

21 Esta reflexión fue gestada en una conversación con Omar Arach, con quien compartí mi primer viaje al Sáhara. 


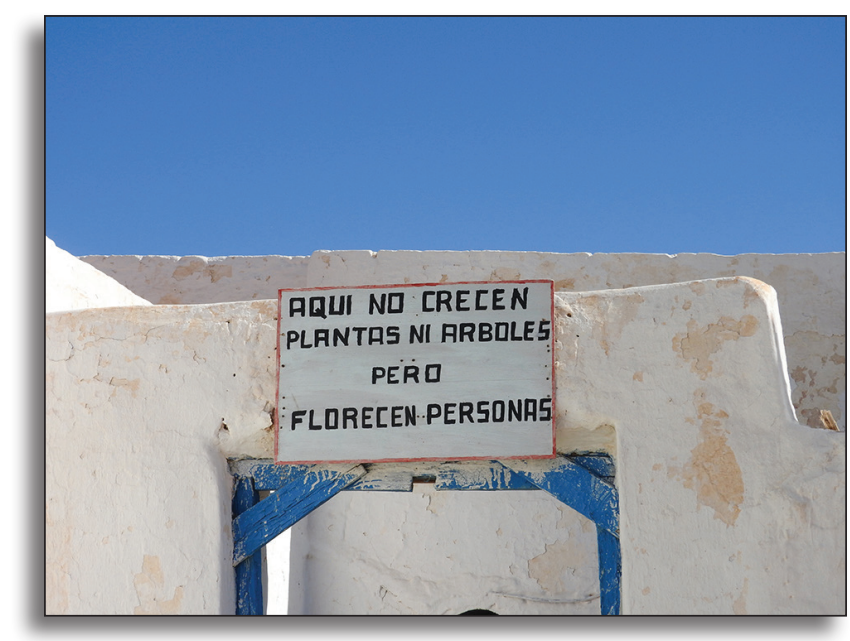

Centro de educación para las personas con diversidad cognitiva. Campo de refugiados de Smara, 2015.

tomar como modelo de "interioridad". La forma exterior al Estado se inspira en el concepto clave de 'asabiya o "fuerte cohesión" de Ibn Jaldún (2008: 216 y ss.). Esta última es una violencia sublimada en aras de la cohesión social y la defensa de la comunidad frente a los enemigos: núcleo de solidaridad que sostiene un orden político tribal itinerante. ${ }^{22}$

Un ejemplo, en el campo de la educación, es el pensamiento crítico de los jóvenes de la escuela Simón Bolívar; otro lo proporciona un beduino apodado "Dr. Castro" (Buyemaa Abdelfatah Lahcen, médico formado en Cuba), ${ }^{23}$ quien tomó a su cargo la educación de la sociedad saharaui a través de los refugiados entre los refugiados, esto es, personas con diversidad cognitiva. El Dr. Castro fundó una escuela diurna en la que se aprende la autonomía transmitiéndola a las familias a fin de que la sociedad saharaui sea hospitalaria con la diversidad humana. Frente a una burocracia de exilio — creada con las mejores intenciones de nuestra civilización- este sabio pastor de cabras ha logrado hacer de la educación algo extraordinario. Esto se debe a que su

22 En la traducción que citamos no aparece el término árabe (en cambio, sí se conserva en la de Juan Feres [Fondo de Cultura Económica 1977]: 275 y ss.). Por considerar que tiene una importancia insoslayable aún en la actualidad, he decidido mencionar la voz original en este trabajo.

23 Entre los saharauis, en determinados ámbitos, exteriores a la familia, el sobrenombre identifica más que el nombre porque este último se escoge dependiendo del azar y de nombres familiares que muchas veces se repiten. 
forma de educar se explica desde el agenciamiento de la vulnerabilidad. Esta última (capacidad de ser herido) es una característica congénita de la especie humana (Levinas 1995: 133 y ss.) que los habitantes del desierto saben asumir mejor que los sedentarios. Por el contrario, nuestra educación moderna se propone combatirla de diversas formas, como si la fragilidad humana fuese una falla (o una vergüenza).

Efectivamente, tal como describe Ibn Jaldún, los nómadas son valientes porque se saben expuestos a constantes peligros en el desierto. Duermen, pero siguen alerta (contrariamente a los citadinos, que nos aflojamos al delegar nuestro coraje en el Estado y su brazo policial y nos refugiamos en pesadas construcciones que en los terremotos llegan a aplastarnos). El Dr. Castro asume la fragilidad humana (asunción de una responsabilidad heterónoma que Levinas caracteriza como maternidad ética) y la devuelve en una forma superior de la hospitalidad: la atención de los vulnerables (discapacitados) entre los vulnerables (refugiados). Atención aquí es lo contrario del asistencialismo paternalista. Como recuerda Benjamin en Malebranche, la atención es la "plegaria natural del alma" (Benjamin 1999: 156-157). Esta es el arma poderosa del centro de educación para las personas con diversidad cognitiva de la wilaya de Smara (cuyo lema se recupera en el epígrafe): máquina de guerra cuyo comandante - memorioso de su origen - se define en su curriculum vitae como "un buen pastor de cabras". 24

\section{Agenciándose las ruinas del progreso}

Hay un cuadro de Klee que se titula Angelus Novus. Se ve en él un ángel, al parecer en el momento de alejarse de algo sobre lo cual clava la mirada. Tiene los ojos desorbitados, la boca abierta y las alas tendidas. El ángel de la historia debe tener ese aspecto. Su rostro está vuelto hacia el pasado. En lo que para nosotros aparece como una cadena de acontecimientos, él ve una catástrofe única, que arroja a sus pies ruina sobre ruina, amontonándolas sin cesar.

Benjamin, Tesis IX

24 Cf. Documental de Marcelo Scotti "Un día con Castro" < https://www.youtube. com/watch?v=SCaYRl_uoGA>, consultado por última vez el 22 de noviembre de 2019. 
En los campos de refugiados de Tinduf, la máquina de guerra nómada se manifiesta en detalles cotidianos, que reflejan formas tan osadas como esperanzadoras de la traducción. Hay una imagen que sorprende al mostrar el agenciamiento beduino del "progreso":

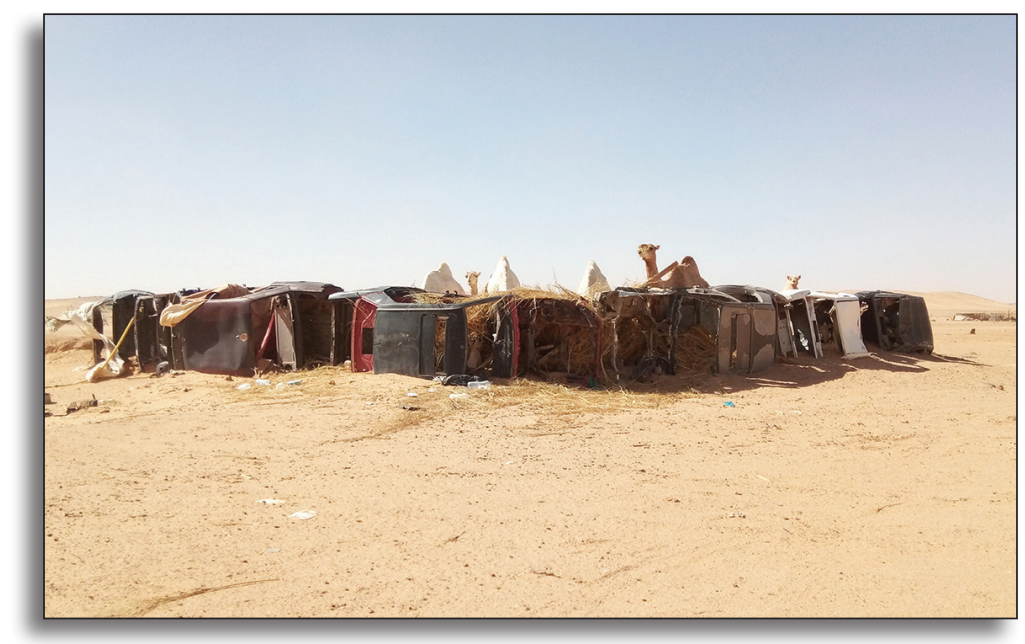

Corral de camellos hecho con chatarra de camionetas, cerca de Rabuni, 2018.

Desde que vi esta escena en 2018 (y volví a buscar en 2019), encontré que no he visto obra de arte con radicalidad más crítica que este producto práctico del ingenio beduino. Si nos ciñéramos al imperativo del progreso industrial y su látigo de la caducidad programada, deberíamos considerar a los camellos como criaturas del pasado y a las camionetas como creaciones geniales que los han desplazado del futuro. Sin embargo, esta escena invierte esa lógica de la (f) utilidad mostrando la persistencia de lo vivo frente a aquello que nace muerto. He aquí la máquina de guerra nómada agenciándose las ruinas del progreso.

Juan José Saer, inspirado en el paisaje postindustrial propio de las latitudes australes de nuestro continente, puede ayudarnos a traducir esta poderosa imagen:

Un televisor recién salido de fábrica resume el conformismo servil de nuestra época; pero uno hecho pedazos junto a un tarro de basura revela la vacuidad irrisoria del mundo en que vivimos más claramente que todas las Vanités del siglo XVII. [...] Toda esa tecnología arcaica a la espera de una improbable segunda oportunidad, supone un anacronismo industrial y económico, pero en cambio, por haberse des- 
embarazado del prejuicio de utilidad y por haber empezado a empastarse otra vez en la naturaleza y a confundirse con ella, ha terminado por ganar su autonomía estética (1991: 237).

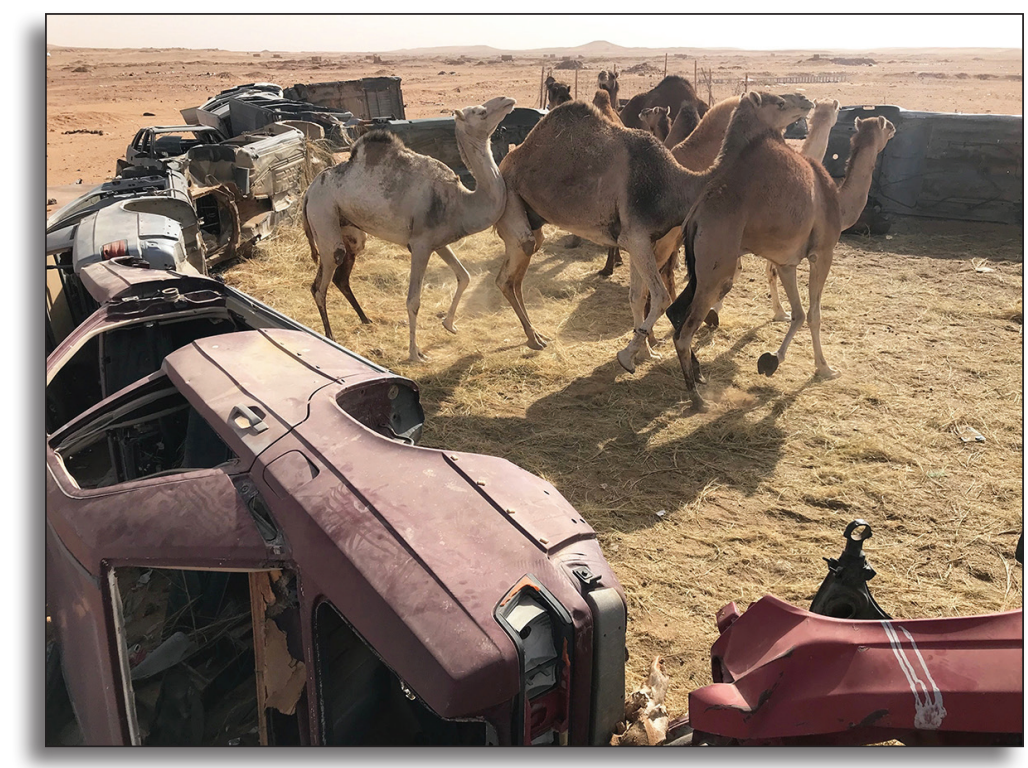

Corral de camellos hecho con chatarra de camionetas, cerca de Rabuni, 2019. Foto tomada por Mariano Villegas Osnaya.

Esta figura testimonia el modo en que la máquina de guerra tradicional somete a la tecnología y su maquinaria avasalladora en una batalla ganada por la vida. Aquí se enfrentan dos saberes: la ciencia nómada o noología (Deleuze y Guattari 2015: 381) 25 se impone ante el saber del Estado (que tantas veces se reduce a oficiar como un agente de compañías multinacionales).

En los campos de refugiados de Tinduf cada día se libran batallas entre estas dos formas del saber, y muchas veces el aparato de Estado consigue ahogar la bravura beduina. Dichas batallas se dan en el sistema de educación, con ciertos visos autoritarios producidos por un conocimiento ajeno que se

25 "La noología, que no se confunde con la ideología, es precisamente el estudio de las imágenes del pensamiento y de su historicidad. [...] Desde que la filosofía se ha atribuido el papel de fundamento, no ha cesado de bendecir los poderes establecidos y de calcar su doctrina de las facultades de los órganos del poder de Estado". Por fuera de este último "La noología choca con contra-pensamientos cuyos actos son violentos, las apariciones discontinuas, la existencia móvil a lo largo de la historia" (Deleuze y Guattari 2015: 381). 
presenta como un huésped hostil; o en la salud, con la confianza ciega de los jóvenes - y no tan jóvenes - en los productos de la industria farmacéutica; o en la economía, con el deslumbramiento ante una teleopulencia siempre inalcanzable que venden las pantallas. (Con el término Estado no me refiero necesariamente a la república de refugiados que, en el exilio, logra tantas veces volver posible lo imposible; sino, sobre todo, al aparato internacional que, frecuentemente con buenas intenciones, no puede comprender el espíritu libertario, el brío y la sencillez de los hijos de las nubes y del desierto.)

Un naturalista que pisó por primera vez el desierto en 1923 y que, en 1994, a los 91 años, bajó por última vez de un camello (Monod 2000: 51), escribió, para cultivar la esperanza, una palabra crítica que resuena en quien se deja acoger por la temporalidad beduina:

El desierto nos enseña de nuevo gestos naturalmente rituales, inscritos, dirigidos incluso por el cosmos. Un hombre sometido a la modernidad y al asfalto está desarmado en semejante mundo, si no se regenera en los dos niveles esenciales que lo estructuran vertical y horizontalmente: la Tierra y el Cielo. El hombre de ciudad no es ya hijo de esos dos elementos nutricios. La eterna división entre Materia y Espíritu debe cesar, como esa idea, en exceso extendida, de que el científico es el primer adepto a esta cesura. [...] El desierto permite escapar de ciertas fuerzas centrífugas nefastas, especialmente concentradas en las ciudades. El hombre está cansado de las ideologías hueras (Monod 2000: 102-103).

\section{Rumbo a un pesimismo organizado (caminos de "opsimismo") ${ }^{26}$}

[...] cada segundo era la pequeña puerta por donde podía entrar el Mesías.

Benjamin, Tesis IX

26 Esta sección se inspira en la creación del escritor palestino Émile Habibi (1989), publicada por primera vez en 1974. El neologismo que se tradujo al español como pesoptimista proviene del árabe al-mutasháłil, لكئشتصل La traducción al hebreo (por Anton Shammas) "opsimista" me parece más lograda que la que lleva el título español (porque une más estrechamente la paradoja cotidiana de quien vive una injusticia y su "optimismo" organiza el "pesimismo" en torno a la certeza de que todo siempre puede ser peor). Agradezco a Shadi Rohana que haya llamado mi atención hacia esta obra y a las distintas traducciones. Aquí evocamos este neologismo porque el humor crítico, reflejado en el texto del escritor palestino, tiene un papel importante en las estrategias de sobrevivencia de los saharauis. 
En el tiempo suspendido de los refugiados, en el paso del tic al tac del reloj se alternan la esperanza y el horror. La desobediencia de los saharauis es portadora de promesa: a pesar de la prohibición de la ONU, salen de los campos de refugiados para trashumar con sus camellos, pero también para "instalarse" (al modo de los nómadas) en los territorios liberados.

En su paradójica ruta, el beduino opsimista (لكئشتمل) retorna al abrigo de la intemperie, lejos de la "protección" y de la "ayuda humanitaria" de la ONU, pero más cerca de su territorio, de su coraje, de su dignidad. Los territorios liberados, con sus formaciones rocosas, atesoran agua. Como la muerte es inexorable, son cada vez más los saharauis que se arriesgan a que esta los sorprenda fuera de la inhóspita hamada y del aparato internacional de sedentarización en los campamentos de refugiados. Más cerca del hogar, que para los beduinos tiene la forma de las acacias al borde de la ruta de los pozos de agua.

Maestros de la asunción de la vulnerabilidad humana: si los saharauis fueron capaces de fundar una República en el exilio (que tiene la forma de una jaima, ${ }^{27}$ esto es, que espera ser plegada para volver a desplegarse en su tierra — por ahora - robada), también lo son de volver al nomadismo y traducir la educación, a nuestros tiempos, por ejemplo, con escuelas nómadas.

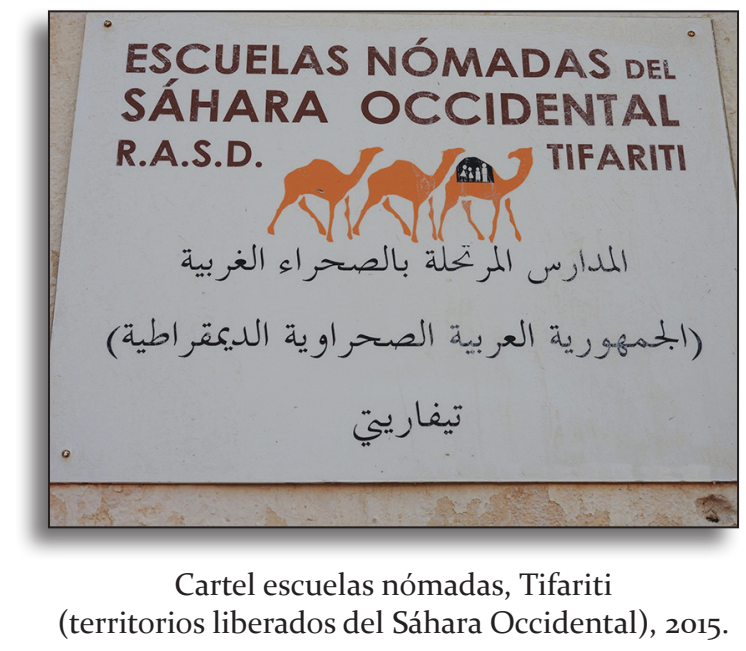

27 En una primera conversación con el Dr. Castro, en 2015, aprendí que para él la república es una jaima. No lo dijo con palabras, pero, ante la pregunta de una reportera sobre qué necesita para su escuela, el pastor respondió "que liberen nuestro territorio y nos dejen volver”. Mientras lo decía, creí entender su gesto de juntar las manos como plegando una jaima y luego volver a abrirlas para desplegarla al mencionar el retorno anhelado. 


\section{De alas heridas y cierto huracán paradisíaco...}

El ángel quisiera detenerse, despertar a los muertos y recomponer lo destruido. Pero un huracán sopla desde el paraíso y se arremolina en sus alas, y es tan fuerte que el ángel ya no puede plegarlas. Este huracán lo arrastra irresistiblemente hacia el futuro, al cual vuelve las espaldas, mientras el cúmulo de ruinas crece ante él hasta el cielo. Este huracán es lo que nosotros llamamos progreso.

Benjamin, Tesis IX

La verdad es un sangrar del corazón. ¡Adiós, viejos nómadas, pastores bíblicos o guerreros fieros! Desde un rincón de esta Península un hombre que simpatizó con vosotros y que también, aquí, es de su tiempo, y vive con su tiempo a cuestas os saluda. Que vuestro Dios, el del Cielo, el que guiaba la nube de quienes os proclamáis hijos, os proteja de los demonios de la tierra, que hoy pueden tomar forma de fosfatos y petróleo, o de economistas distinguidos.

Julio Caro Baroja, 3 de enero de 1976

Si la crítica benjaminiana al progreso se me hizo patente en los dos primeros viajes, en el tercero la imagen del Angelus novus de la novena tesis tuvo un rol protagónico. Rumbo al aeropuerto de Tinduf, en mi viaje de regreso, pensé en sus alas (arremolinadas por ese huracán proveniente del Paraíso al que llamamos “progreso”). La pregunta obligada es ¿por qué precisamente el Paraíso, aquel lugar idílico, sería el origen de algo tan destructor como un huracán? El Edén nombra, también, al exilio primordial (Génesis 3:24) (Dujovne et al. 1998). Vedado el retorno, el añorado jardín está custodiado por la espada inquieta y flamígera de los querubines.

Vuelve entonces a la memoria el poeta Mahmud Darwish, quien lamenta que en la lengua árabe, la palabra pájaro (Tair رئأس) haya dado lugar al término que designa al avión (Taiara ثري) , siendo esta última el femenino de la primera. ${ }^{28}$ Solo la mirada desprejuiciada del poeta (aquel que dice enve-

28 Cf. Darwich ([1987] 1994: 15) «Une des pires choses de la langue arabe, c'est peut-être que l'avion - tâira- soit le féminin de l'oiseau -tâïr. Les oiseaux poursuivent leur chant, affirment leur présence au milieu du fracas des bombardements maritimes». 
jecer sin dejar crecer al niño olvidado) es capaz de cuestionar "lo peor" de su lengua amada: “¿quién dice que el avión sea el femenino del pájaro?” (El último es más fuerte, pues se ha demostrado en Beirut, año 1982, capaz de afirmar "su presencia en medio del estruendo de los bombardeos marítimos" [Darwich 1994: 95].)

En Beirut, dice el poeta, "los pájaros cesaron su canto; se pusieron en guardia por la guerra porque su pedazo de cielo no está más a salvo" (Darwich 1994: 15). En el Sáhara temen al descanso, pues esto significa jugarse la vida, sigilosos, entre las minas. Me pregunto: cuando nazcan estas aves, ¿hacia dónde darán sus primeros pasos? Ojalá que, tanto su madre como ellas, sepan alejarse de la mina. La foto que sigue es tal vez el retrato más fiel de todos aquellos que nacen en campos de refugiados.

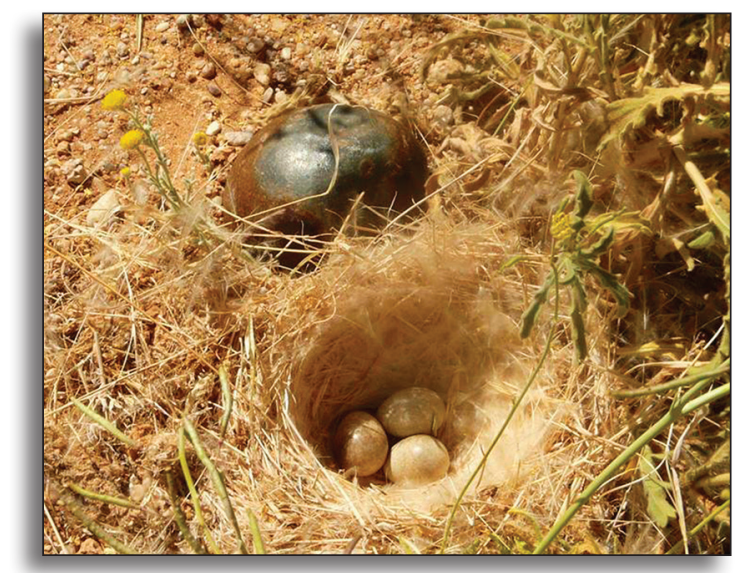

Foto cortesía de SMACO: nido de pájaros junto a una mina en el Sáhara Occidental.

Es común asociar alas con libertad. Pero a veces estas se encuentran aprisionadas o heridas. El poeta deplora que las alas del pájaro, en su lengua, sean galvanizadas en la voz femenina que designa un avión y por eso advierte que volar no es suficiente para ser pájaro (Darwich 1994: 15). Los aviones pueden ser de guerra; entonces, desde la altura matan. Y aun si no son de guerra, contaminan e invaden el hábitat de las aves. ${ }^{29}$ La posibilidad de volar entre

29 Vuelve a la memoria el inicio del Río sin orillas de Juan José Saer: "Espanto y vulgaridad son el patrimonio principal de los aviones. No contentos con colocarnos, a toda velocidad, de la tierra firme en que estábamos, a diez mil metros de altura, poniendo a prueba la paciencia de sus motores, los profesionales de lo aéreo agravan 
aeropuertos, munidos de visas, tampoco nos vuelve libres (no lo hará mientras a tantos otros les esté vedado, mientras haya refugiados cuyo pedazo de suelo tampoco se encuentre a salvo).

Iniciamos este artículo "aterrizando" en un avión comercial para dirigirnos a los campos de refugiados saharauis y se muestra imposible montarse a otra aeronave para dejarlos atrás. Los ojos del ángel, en medio del huracán, no pueden retornar a sus órbitas mientras los nómadas sigan suspendidos en su espera.

Cierro este artículo mientras hace días arde la Amazonia y el presidente de Brasil se regodea de los negocios que vendrán cuando se extingan sus habitantes originarios. $3^{30}$ Cedo mi palabra a aquel científico que del desierto aprendió el misticismo y la potencia crítica de la ecopolítica nómada:

El desierto progresa (en el Sáhara líbico, por ejemplo, la lluvia caerá dentro de cien o de mil años) por acción de los vientos, de la falta de lluvia, del agotamiento de las capas freáticas y de los oasis, por la desaparición de cualquier vegetación. Para los nómadas eso significa la hambruna. Sin embargo, los desiertos pueden recuperar la humedad. [...] ¿Cuándo será el desierto, de nuevo, una pradera? Hace diez mil años el desierto era una sabana donde vivían jirafas y elefantes. El clima los exterminó. [...] Salvar a los nómadas forma parte de nuestra tarea, tanto como buscar y encontrar los orígenes del planeta para extraer de ellos, además de hipótesis científicas, algunas reflexiones filosóficas. El hombre prehistórico era más sabio que el de la cibernética. Ese depredador, campeón de la destrucción, del destrozo y el beneficio, saquea los recursos naturales y acumula artilugios bélicos (Monod 2000: 65-66).

\section{Bibliografía}

Arendt, Hannah ([1943] 2009). "Nosotros, los refugiados”, Escritos judíos, Kohn Jerome y Ron H. Feldman (ed.). Madrid, Paidós: 353-365.

Barona Castañeda, Claudia, y Jorge Gamaliel Arenas (2016). "La República Árabe Saharaui Democrática. Reflexiones sobre un Estado en el exilio”, en Isaías Barre-

la situación creyéndose obligados a munirnos de un entorno agradable, que para ellos se encarna en todos los lugares comunes que ha concebido la cultura del ocio" (Saer 1991: 13).

30 <https://www.excelsior.com.mx/global/indigenas-estorban-en-desarrollodel-amazonas-bolsonaro/1328805?fbclid=IwAR2SBf37QTkhfnp4_86yGUsIn4M Kio8_BQhD-gPo4NUt2mqoxOTJOx8yoAo>, consultado por última vez el 22 de noviembre de 2019 . 
ñada y Raquel Ojeda (ed.), Sáhara Occidental 40 años después. Madrid, Catarata: 57-65.

Benjamin, Walter ([1940] 2014). "Sobre el concepto de historia”, en Dialéctica en suspenso. Fragmentos sobre la historia, trad., introd. y notas Pablo Oyarzún Robles. Santiago de Chile, LOM: 37-83. [También se consultó comparativamente la versión de Bolívar Echeverría (2008). Tesis sobre la historia y otros fragmentos. México, Ítaca/Universidad Autónoma de la Ciudad de México.]

Benjamin, Walter ([1934] 1999). "Franz Kafka”, Para una crítica de la violencia y otros ensayos. Iluminaciones IV. Madrid, Taurus: 135-161.

Benveniste, Émile (1966). "L'hospitalité”, Le vocabulaire des institutions indo-européennes, T. I. Paris, Gallimard: 87-101.

Beristáin, Carlos M., y Eloísa GonzÁlez Hidalgo (2012). El oasis de la memoria I y II. Bilbao, Hegoa.

Beristáin, Carlos M., y Francisco Etxeberria Gabilondo (2013). Meheris. La esperanza posible. Fosas comunes y desaparecidos saharauis identificados. Bilbao, Hegoa/Aranzadi. Zientzia Elkartea.

Beristáin, Carlos M., Alonso Gil y Federico GuzMán (2013). Memorias nómadas. Dolor y resistencia en el Sáhara Occidental. Barcelona, Icaria/Hegoa.

BERISTÁIn, Carlos M. (dir.) et al. (2015). Los otros vuelos de la muerte. Bombardeos de población civil en el Sáhara Occidental. Bilbao, Hegoa.

Bibliotecas Bubisher del SÁhara Occidental, en <http://www.bubisher.org/>, consultado por última vez el 22 de noviembre de 2019.

BraicA, Habuha (2006). "El muro del Sáhara Occidental: acecho de la muerte”, Colaboraciones, núm. 1073, 6 de julio. Madrid, Grupo de Estudios Estratégicos.

CARo BAROJA, Julio (20o8). Estudios saharianos [Consejo Superior de Investigaciones Científicas 1955]. Madrid, Sgarit.

DARWICH, Mahmud ([1987] 1994). Une mémoire pour l'oubli. Arles, Actes Sud.

DARWISH, Mahmud (2017). "Discurso del 'indio'. El penúltimo ante el 'hombre blanco"” en Silvana Rabinovich (ed.), Retornos del Discurso del "indio" (para Mahmud Darwish). México, Universidad Nacional Autónoma de México/Instituto de Investigaciones Filológicas/Apofis: 17-24.

Deleuze, Gilles, y Felix Guattari (2015). “Tratado de nomadología”, Mil mesetas. Valencia, Pre-Textos: 359-431.

DerridA, Jacques (200o). "Hostipitality”, Angelaki Journal of the Theoretical Humanities, vol. 5, núm. 3, diciembre, London/Estambul: 3-18.

Dujovne, León, Manasés Konstantynowski y Moisés KonstantynowsKi (1998). La biblia, versión castellana. Buenos Aires, Ediciones Sigal.

EsCUELA DE CINE DEL SÁHARA OCCIDENTAL, en <http://www.escueladecinedelsahara.org/>, consultado por última vez el 22 de noviembre de 2019.

ExCELSIOR (2019). "Indígenas estorban en 'desarrollo' del Amazonas: Bolsonaro", (6 deagosto), en <https://www.excelsior.com.mx/global/indigenas-estorban-en-desa rrollo-del-amazonas-bolsonaro/1328805?fbclid=IwAR2SBf37QTkhfnp4_86yGUsI n4MKio8_BQhD-gPo4NUt2mqoxOTJOx8yoAo>, consultado por última vez el 22 de noviembre de 2019 . 
HABIBI, Émile (1989). Los extraordinarios hechos que rodearon la desaparición de Saíd, padre de calamidades, el pesoptimista. Barcelona, Muchnik.

IBN JALDún ([1377] 2008). Introducción a la historia universal (Al Muqaddima). Córdoba, Almuzara. [También se consultó comparativamente la edición de Juan Feres (1977). México, Fondo de Cultura Económica.]

Jiménez SÁnchez, Carolina (2014). El conflicto del Sáhara Occidental: el papel del Frente Polisario. Eumed.

LANGA MARTínEZ, Laura (2016). “Transformaciones en los campamentos: retóricas del humanitarismo y cuatro inexactas disyuntivas”, en Isaías Barreñada y Raquel Ojeda (ed.), Sáhara Occidental 40 años después. Madrid, Catarata: 93-103.

LEVINAS, Emmanuel ([1974] 1995). De otro modo que ser o más allá de la esencia. Salamanca, Sígueme.

MARTínez Milán, Jesús María (1991). “La descolonización del Sahara occidental”, Espacio, Tiempo y Forma, Serie V, Historia Contemporánea, t. IV: 191-200. En línea: $<$ http://e-spacio.uned.es/fez/eserv/bibliuned:ETFSerie5-3AıBBBo5-8E9B-9414B4E4-AFCoA6DE072D/Documento.pdf>, consultado por última vez el 22 de noviembre de 2019.

Mejía LARA, Airy Sindik (2018). Sin aire para el regreso. Novela de la primera intifada de la primavera árabe. México, Universidad de Guadalajara.

Monod, Théodore (200o). Peregrino del desierto. Barcelona, José J. Olañeta, ed.

Moya, Conchi (2010). Las treinta y dos batallas de Aminetu Haidar. Madrid, Bubok.

Naciones Unidas, Mantenimiento dela Paz, "Minurso, ficha informativa”, en <https:// peacekeeping.un.org/es/mission/minurso $>$, consultado por última vez el 22 de noviembre de 2019.

NACIONES UnidAS (1991). Resolución 690, en <https://undocs.org/es/S/RES/690>, consultado por última vez el 22 de noviembre de 2019 .

RABinOVich, Silvana (2018). Interpretaciones de la heteronomía. México, Universidad Nacional Autónoma de México/Instituto de Investigaciones Filológicas.

SAER, Juan José (1991). El río sin orillas. Buenos Aires, Alianza.

Schubert-Wurr, Zazie, y Manuel Domínguez (2017). Mariem Hassan. La voz indómita (del Sáhara Occidental). Madrid, Nubenegra.

\section{Videos}

Democracy Now! (2018). "Four days in occupied Western Sahara", en <https://www. youtube.com/watch?v=smg97ib_yfM>, consultado por última vez el 22 de noviembre de 2019.

GüELL, Lluís María (dir.) (2011). Gdeim Izik. El campamento de la resistencia saharaui, en <https://www.youtube.com/watch?v=KT48osFZsbY>, consultado por última vez el 22 de noviembre de 2019.

Los Tigres Del NorTe (2001). “Somos más americanos”, en <https://www.youtube. com/watch? $v=$ LN3obcuoebo $>$, consultado por última vez el 22 de noviembre de 2019. 
Nushatta Foundation (2019). "Clouds of tension rise in Western Sahara" (20 de agosto de 2019), No te olvides del Sahara Occidental, en <https://noteolvides delsaharaoccidental.org/nushatta-foundation-clouds-of-tension-rise-in-westernsahara>, consultado por última vez el 22 de noviembre de 2019.

ScOTTI, Marcelo (2014). "Un día con Castro"<https://www.youtube.com/watch?v=SCa YRl_uoGA>, consultado por última vez el 22 de noviembre de 2019.

\section{Silvana Rabinovich}

Doctora en Filosofía, investigadora en el Seminario de Hermenéutica del Instituto de Investigaciones Filológicas de la UNAM, tutora en el Posgrado en Filosofía de la Facultad de Filosofía y Letras de la UNAM, es responsable del Proyecto PAPIIT IN 401119 "Heteronomías de la justicia: territorialidades nómadas". Нa publicado, entre otros: La Biblia y el drone: sobre usos y abusos de figuras bíblicas en el discurso político de Israel (2013), Heteronomías de la lectura (2013), Interpretaciones de la heteronomía (2018), así como Retornos del Discurso del "Indio" (para Mahmud Darwish) (2018), como editora, y Heteronomías de la justicia: de exilios y utopías (2019), como coeditora. 